\title{
¡No sé si reír o llorar! \\ Secuencia de actividades verbo-tonales para la pronunciación del español
}

\author{
LARA GARCÍA GÓMEZ \\ Universidad de Alicante \\ lgg57@alu.ua.es \\ ANA GONZÁLVEZ GONZÁLEZ \\ Universidad de Alicante \\ agg148@alu.ua.es \\ PAULA MUÑOZ RUIZ \\ Universidad de Alicante \\ pmr34@alu.ua.es
}

Resumen: En este artículo se pretenden desarrollar una serie de actividades verbotonales dirigidas a estudiantes sinohablantes, que poseen determinadas desventajas lingüísticas respecto al español. Por una parte, se plantea favorecer la expresión y reconocimiento de las emociones, mientras que por otra parte se pretende fomentar la práctica del sonido [r]. La propuesta didáctica se compone de tres fases donde primero se presentan y practican las entonaciones del español, después se tratan las emociones asociadas con colores en base a la película Del revés (favoreciendo primero la destreza de comprensión auditiva y, después, la expresión oral). En la última fase los estudiantes ponen en práctica lo visto anteriormente a través de un juego lúdico. Así, con esta sesión didáctica, se pretende favorecer la competencia léxica, gramatical y pragmáticakinésica que afecta a este colectivo en parte debido a motivos socioculturales.

Palabras clave: entonaciones, emociones, sinohablantes, metodología verbo-tonal.

Abstract: This article aims to develop a series of verbo-tonal activities directed to Chinese speakers' students who have certain linguistic disadvantages in relation to Spanish. On the one hand, it is proposed to work out well the expressions and recognition of main emotions while, on the other hand the intention is to encourage the practice of sound [r]. This didactic proposal is made up of three stages: first, the Spanish intonations are presented, then students work with emotions that are associated with the different colours that appear in the movie Inside Out (practising listening and speaking). In the last stage students put into practice the previous stages through a playful game. Thus, with this didactic proposal, students are able to work the lexical, grammatical and pragmatic-kinesics competences, that affect this nationality due to sociocultural reasons.

Key words: intonations, emotions, Chinese learners, verbo-tonal method. 


\section{Introducción}

La presente secuencia de actividades verbo-tonales para la enseñanza de español está diseñada para alumnado de origen chino. Esta propuesta en concreto se destina a estudiantes con un nivel de español intermedio-avanzado (B1-B2) según el Marco Común Europeo de Referencia y temporalizado para una sesión de unos treinta/cuarenta minutos. Se destina principalmente para un grupo reducido de tres a cinco estudiantes con el propósito de favorecer, de este modo, la atención. Aparte, para el nivel que se proponen estas actividades, el estudiante tiene ya una base más avanzada tanto del aspecto gramatical como del léxico del español, pero generalmente no es igual en cuanto a la entonación que marcan las emociones del ser humano. De esta manera, como afirman Alfonzo de Tovar y Santana Alvarado (2015), la población china, en general, dista culturalmente de la población española o hispanoamericana, siendo estas últimas de carácter más extrovertido y emotivo, donde las emociones van ampliamente asociadas por cómo se habla y demuestra lo que se quiere expresar. La población sinohablante es más introvertida y tiende a cohibir sus emociones interiorizándolas. Por consiguiente, para un aprendizaje y conocimiento íntegro del español como lengua extranjera se precisa conocer y practicar este aspecto cultural.

Por todo ello, los elementos que pretendemos trabajar en esta propuesta didáctica son las curvas melódicas del español, concretamente la declarativa, interrogativa y suspendida a través de las emociones, junto a un léxico que contenga el sonido [r] en posición inicial, intervocálica y final.

Para conseguir estos objetivos se ha utilizado la película de animación Del revés., estrenada en 2015 por Pete Docter y Ronnie del Carmen. Los protagonistas servirán de hilo conductor durante gran parte de la sesión, siendo: Enfado, Tristeza, Alegría y Miedo. Junto a ellos el estudiante irá familiarizándose con las emociones hasta lograr comprenderlas y poner en práctica, en consonancia, con el sonido [r].

\subsection{Problemática de los sinohablantes}

El chino se encuentra dentro de la familia sinítica o chino-tibetana, que a su vez comprende centenares de lenguas habladas por más de mil de millones de personas en el continente asiático. El español es una lengua romance, dentro de la rama de lenguas que comprende la familia indoeuropea, donde pertenecen la mayor parte de las lenguas habladas en Europa. Por lo tanto, ambas lenguas no cuentan con ninguna relación en el aspecto genealógico, lo que dificulta el proceso de aprendizaje de español por parte de los estudiantes sinohablantes al encontrarse con una lengua desconocida y totalmente diferente.

Esta propuesta didáctica se centra en la confusión asociada al fonema consonántico vibrante múltiple $/ \mathrm{r} /$, el cual los estudiantes chinos no poseen en su lengua y confunden con el fonema consonántico alveolar lateral /1/. La consonante [r] que existe en chino es un sonido fricativo, postalveolar, sonoro cuya transcripción fonética es [z] aunque a veces también se puede realizar como aproximante postalveolar, sin la fricción característica de las fricativas, y en este caso se transcribe como [.] (Lora Bravo 2017). Ante esta problemática debemos proponer al alumnado ejercicios destinados a reconocer los sonidos y letras que representan estos fonemas así como ayudar a fijar la pronunciación. Se trabaja entonces para que conozcan, escuchen y pronuncien con precisión, favoreciendo así una mejor comprensión auditiva. 
Respecto al elemento suprasegmental que se trabaja en esta propuesta didáctica, se trata de la entonación del español, relacionada con las emociones, las cuales se expresan y contextualizan en las distintas lenguas a través de una serie de mecanismos y construcciones, tanto con significado literal como metafórico, donde el aspecto pragmático notablemente. Así, los términos emocionales no se traducen fácilmente a otro idioma aun siendo emociones básicas, ya que se presentan y expresan de una manera u otra según ciertas lenguas y culturas como en este caso, comparando el español frente al chino. De esta manera, el alumnado sinohablante que se inicia en el aprendizaje del español ha de hacer frente a una serie de factores que van más allá de lo cognitivo. Estudiantes en nivel A1 son más propicios al choque cultural que conlleva estudiar una lengua que posee una gran diferencia cultural, aunque su condicionamiento depende, además, de factores como la personalidad, la experiencia en situaciones de comunicación intercultural e incluso de factores ambientales.

\subsection{Curvas melódicas del español}

En La melodía del habla: acento, ritmo y entonación de Font Rotchés y Cantero (2008) se habla de la importancia de los elementos prosódicos en la enseñanza de lenguas extranjeras o segundas lenguas. Si bien, rara vez se ven incluidos en los manuales, han de tenerse muy en cuenta, puesto que, si no fuera por ellos, se hablaría de forma desorganizada y sin melodía. La propuesta didáctica planteada se propuso para trabajar con las emociones, pero es necesario conocer antes las diferentes curvas melódicas del español. Así, atendiendo a los autores mencionados anteriormente, se distinguen cuatro modelos entonativos básicos:

-La entonación declarativa o neutra que "se caracteriza por un anacrusis con un ascenso máximo de un $40 \%$ hasta la primera vocal tónica o primer pico; por el cuerpo, en declinación suave y constante, y por la inflexión final que se sitúa en una horquilla de entre un 10-15\% de ascenso y un 40\% de descenso" (Font y Cantero 2008: 33) (ver figura 1). Es la entonación correspondiente en casos en los que un hablante dice, por ejemplo: Me gusta mucho el chocolate.

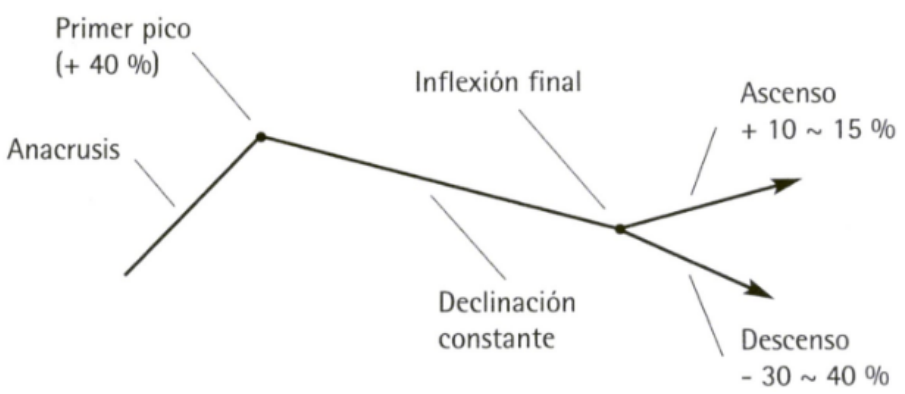

Figura 1. Modelo de la entonación declarativa o neutra según Font y Cantero (2008)

-La entonación interrogativa se da en casos como: ¿Te gusta el chocolate? Está caracterizada "por un anacrusis con un ascenso máximo de un $40 \%$ hasta la primera vocal tónica o primer pico; por el cuerpo, en declinación suave y constante y por la inflexión final que presenta un ascenso muy pronunciado, mínimo de un $80 \%$." (Font y Cantero 2008: 34) (ver figura 2). 


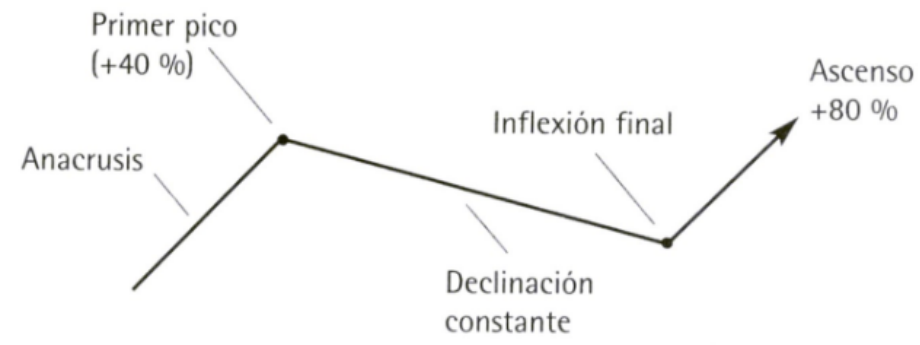

Figura 2. Modelo de la entonación interrogativa según Font y Cantero (2008)

-La entonación enfática aparece en: ¡Me encanta el chocolate!, donde la línea melódica "se presenta con varios picos y declinaciones en cualquier punto del contorno." (Font y Cantero 2008: 34) (ver figura 3).

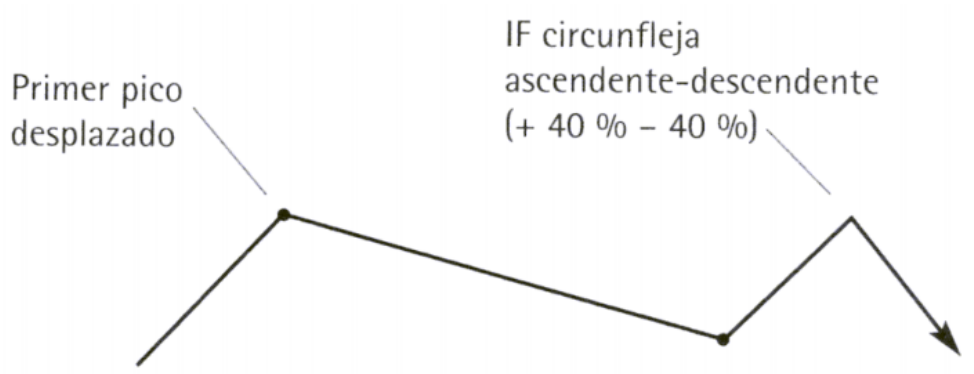

Figura 3. Modelo de la entonación enfática según Font y Cantero (2008)

-La entonación suspendida, habiendo dos tipos. Por un lado, donde "la melodía ha sido truncada antes de llegar a la inflexión final", en ejemplos como: Me gustan las fresas, el chocolate, el helado... Por otro lado, con "un anacrusis con un ascenso máximo del $40 \%$ hasta la primera vocal tónica o primer pico; por el cuerpo, en declinación suave y constante, y con inflexión final que presenta un ascenso entre un 10-15\% hasta un 80\%." (Font y Cantero 2008: 35) (ver figura 4). Se trata de enunciados en los que el hablante quiere indicar que aún no ha terminado y que tiene el turno de palabra.

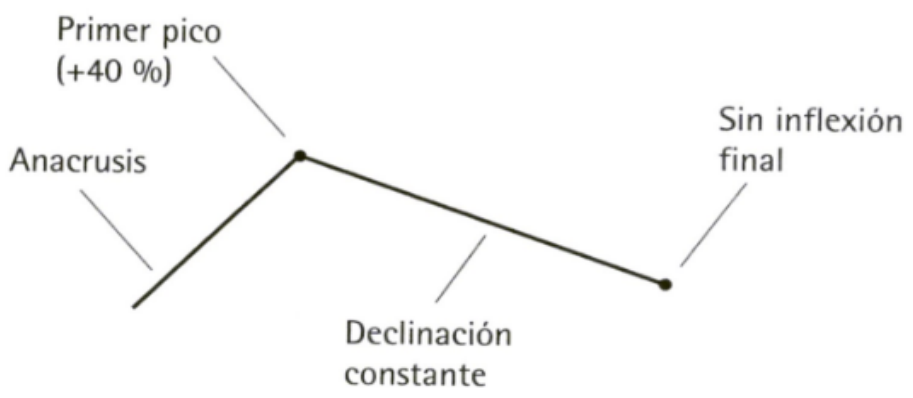

Figura 4. Ejemplo de entonación suspendida según Font y Cantero (2008)

\section{Unidad Didáctica}

La propuesta didáctica pasa a estructurarse a continuación para un mejor conocimiento del fundamento de esta, así como para entender su funcionamiento y desarrollo. 


\subsection{Tabla resumen de la Unidad Didáctica}

\begin{tabular}{|c|c|}
\hline \multicolumn{2}{|r|}{ ¡No sé si reír o llorar! } \\
\hline Nivel & Intermedio-avanzado (B1-B2) \\
\hline Objetivos & $\begin{array}{l}\text { - Practicar tres de las curvas melódicas del español (declarativa, } \\
\text { interrogativa y suspendida). } \\
\text { - Practicar el sonido [r]. } \\
\text { - Favorecer la expresión y conocimiento de las emociones. } \\
\text { - Potenciar y desarrollar la dimensión perceptiva, receptiva y } \\
\text { productiva. }\end{array}$ \\
\hline $\begin{array}{l}\text { Lengua materna } \\
\text { del aprendiente }\end{array}$ & $\begin{array}{l}\text { Principalmente lengua china (sinohablantes), pero es posible } \\
\text { llevarla a cabo en cualquier aprendiente con problemas con el } \\
\text { sonido [r] (elemento segmental) así como con la expresión de } \\
\text { emociones asociadas a diferentes entonaciones (elemento } \\
\text { suprasegmental). }\end{array}$ \\
\hline Contenidos & $\begin{array}{l}\text { - Léxico con el sonido [r] } \\
\text { - Entonaciones } \\
\text { - Curvas melódicas del español } \\
\text { - Emociones básicas }\end{array}$ \\
\hline Destinatarios & Jóvenes y adultos. \\
\hline Dinámica & Trabajo individual, así como alternancia con el trabajo grupal. \\
\hline Duración & 30-40 minutos (1 sesión, sujeta a posibles cambios) \\
\hline Materiales & $\begin{array}{l}\text { Ordenador, Power Point, película Del revés, personajes en } \\
\text { palitos, tarjetas, dado. }\end{array}$ \\
\hline $\begin{array}{l}\text { Orientaciones } \\
\text { para el profesor }\end{array}$ & $\begin{array}{l}\text { Se trata de una propuesta aplicable a diferentes grupos de edad } \\
\text { adaptándose al nivel de los destinatarios. Se recomienda } \\
\text { realizar en sesiones que impliquen no más de cuatro } \\
\text { participantes, ya que se debe tener en cuenta la concentración, } \\
\text { así como el ritmo en el que los aprendientes asimilan. }\end{array}$ \\
\hline
\end{tabular}

Tabla 1. Tabla resumen de la Unidad Didáctica

\subsection{Procedimiento de la Unidad Didáctica}

A continuación, se describe fase a fase, la secuenciación de actividades para esta propuesta de clase verbo-tonal:

\section{Fase 1 $1^{\mathrm{a}}$ : Presentación de las diferentes entonaciones del español}

Para comenzar, se trabajan las entonaciones básicas del español mediante tres de las curvas melódicas básicas asociadas a estas, en cuanto a las mencionadas por Font Rotchés y Cantero (2008) siendo la declarativa, la enfática y la suspendida. Se presenta 
cada una de las curvas melódicas al mismo tiempo que se muestra una imagen de una montaña rusa que se mueve realizando tres distintos movimientos, uno por cada cambio de diapositiva en la presentación: subida, bajada o en línea recta. Observar estos movimientos progresivamente va a ayudar a los aprendientes a detectar, rápida y visualmente, las diferencias entre las emociones básicas, haciendo un paralelismo entre cómo sube, baja o se mantiene la entonación al hablar.

De este modo, se muestra a los alumnos en primer lugar la imagen de una montaña rusa que se mueve en dirección horizontal (ver imagen 1), al mismo tiempo que se enuncia un ejemplo sonoro con la entonación que se quiere trabajar, por parte del docente. Simultáneamente, se hace el gesto con la mano en sentido horizontal, para dar más significación a la entonación en cuestión, es decir, en este caso, la declarativa.

Estos ejemplos pueden servir de apoyo para favorecer la asociación que se quiere conseguir por parte de los alumnos, considerando siempre que guarden una entonación que asemeja a enunciaciones acabadas y ayude a retener la secuencia: movimiento horizontal de la montaña rusa-gesto en línea recta de la mano-entonación declarativa (en este caso):

1. Hay un ratón en la cocina.

2. El tiburón está cerca.

3. Juan siente dolor en el corazón.

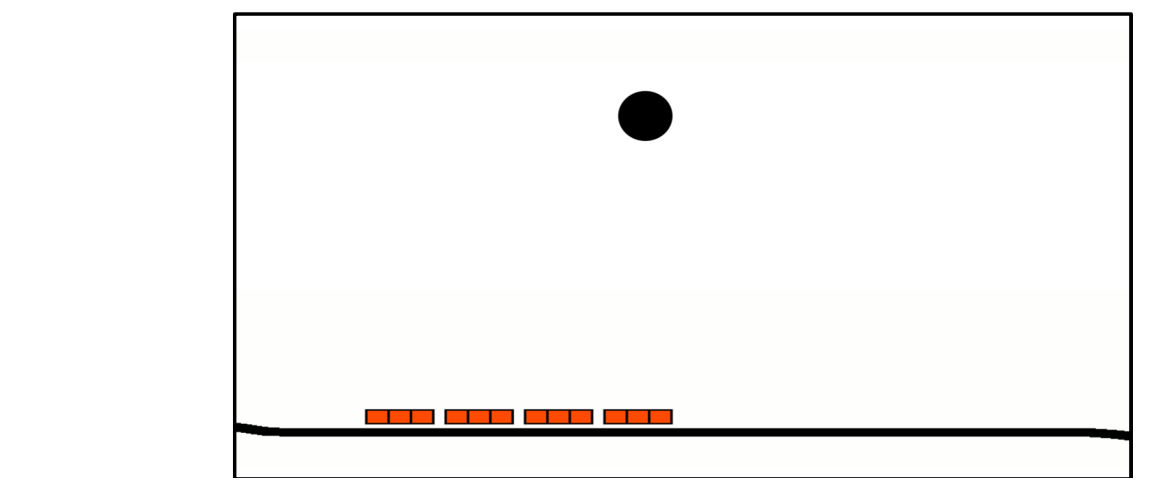

Imagen 1. Captura de la animación en movimiento para asociar con la entonación declarativa

Tras mostrar los enunciados anteriores, se trata de que los estudiantes se familiaricen con la entonación percibiendo esencialmente su melodía. Por ello, el docente hace uso del tarareo para fijar el gesto entonativo y reforzar más aún la "música" propia de la entonación.

A su vez, los estudiantes empiezan a familiarizarse y a llevar a cabo una percepción inconsciente del sonido [r] ya sea en posición inicial (ratón), intermedia (tiburón) y final (dolor), siguiendo esta progresión atendiendo al nivel de dificultad que implica en alumnos sinohablantes realizar su articulación según la posición que ocupa el sonido. Por consiguiente, al mismo tiempo que se introducen las curvas melódicas básicas, se presenta el léxico que además se trabajará en posteriores tareas de la sesión.

Siguiendo con esta fase, en el segundo caso se muestra ahora a los estudiantes la entonación interrogativa, mediante la asociación de una animación de una montaña rusa, esta vez realizando un movimiento de ascenso (ver imagen 2), que se asemeja a la "música" de esta entonación. Se lleva a cabo entonces el mismo procedimiento que antes: se tararea la entonación, se realiza un gesto ascendente con la mano, se incorpora 
un léxico con [r] y se pronuncian los mismos enunciados, pero modificando ahora las características melódicas propias de su emisión, siendo:

1. ¿Hay un ratón en la cocina?

2. ¿El tiburón está cerca?

3. ¿Juan siente dolor en el corazón?

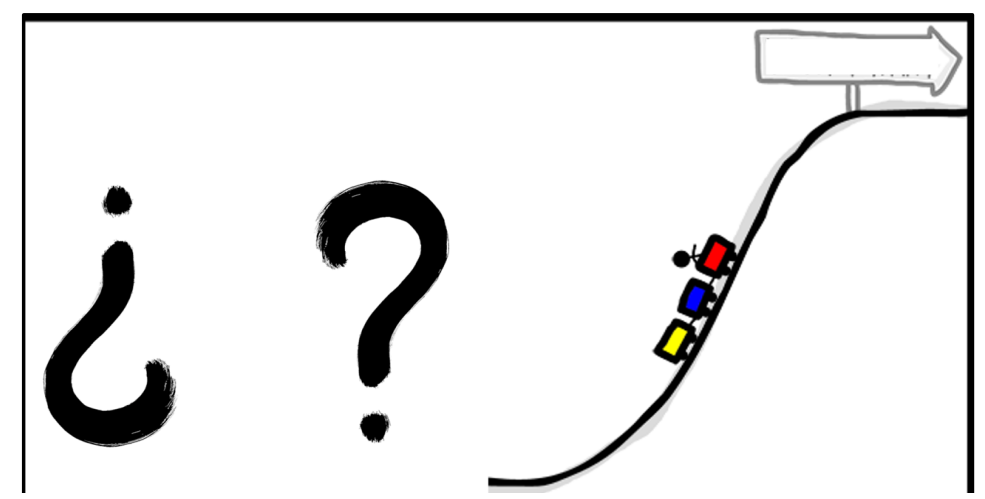

Imagen 2. Captura de la animación en movimiento para asociar con la entonación interrogativa

Para finalizar esta fase, se presenta otra animación de una montaña rusa, en este caso realizando un movimiento de descenso (ver imagen 3) que se asemeja a cómo se habla con entonación suspendida. Se trabaja con los estudiantes de la misma manera que en las dos situaciones anteriores, con enunciados asociados a esta entonación e incluyendo léxico que incorpora el sonido [r] en distintas posiciones, siendo:

1. Hay un ratón en la cocina, el salón, el baño...

2. El tiburón está cerca, nadando lentamente...

3. Juan siente dolor en el corazón, en la espalda, las piernas...

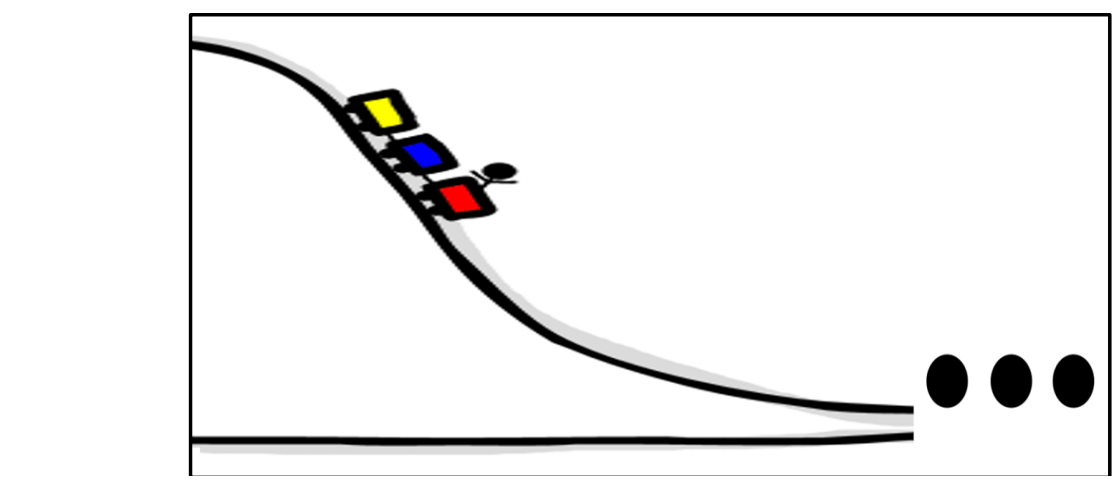

Imagen 3. Captura de la animación en movimiento para asociar la entonación suspendida

También hay que considerar que, en el conjunto de esta fase, se van mostrando a la vez signos mnemotécnicos para recordar mejor las entonaciones y conseguir una mejor asimilación de estas, haciendo que estos guarden relación con cómo "suena" cada entonación. Estos símbolos son: un punto (entonación declarativa), signos de interrogación (entonación interrogativa) y puntos suspensivos (entonación suspendida).

\section{Fase $2^{\text {a }}$ : Presentación de emociones}

Es en esta segunda fase cuando se introducen las emociones como tal, mediante un tráiler, editado, de la película Del revés. Se proyecta el vídeo para que el alumnado 
observe y escuche a cada uno de los personajes (ver imagen 4), relacionando la manera en que cada uno habla con las emociones básicas que se trabajarán: alegría, tristeza, enfado y miedo. Al ser un vídeo breve, es conveniente volver a proyectarlo para asegurar la asociación de cada personaje con una determinada emoción, así como con un color (azul-tristeza, morado-miedo, amarillo-alegría, rojo-enfado).

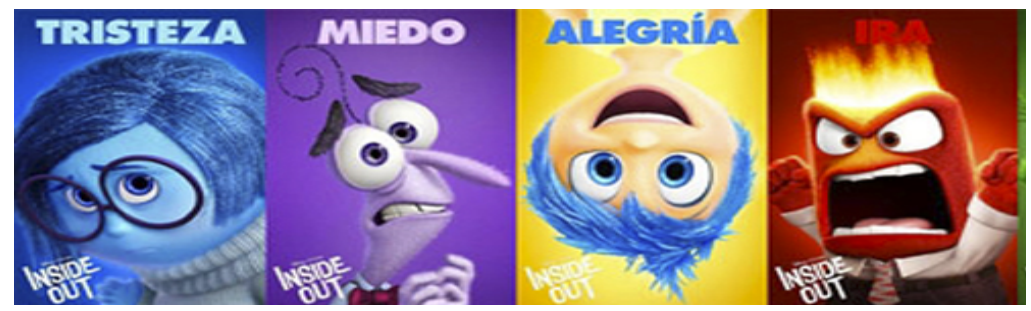

Imagen 4. Personajes de la película Del revés asociados a emociones

Tras esto, se reparte a cada estudiante cuatro tarjetas con imágenes de cada uno de los personajes de la película (ver imagen 5). Se realiza entonces una tarea en la que han de escuchar unos audios previamente seleccionados y extraídos de la película, habiendo dos por cada emoción/personaje. Se escucha cada uno dos veces, y se hace una cuenta atrás para que los aprendientes, a la vez, levanten una de las cuatro tarjetas en función del personaje y la emoción que creen haber percibido en el audio.

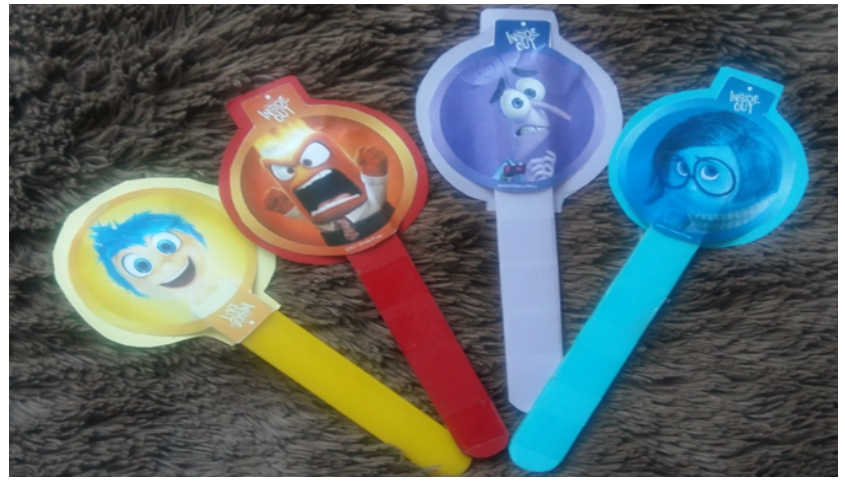

Imagen 5. Palitos representativos de los personajes de la película para usar en la fase $2^{a}$

\section{Fase $3^{\mathrm{a}}$ : Actividad lúdica $[\mathrm{r}]+$ emociones}

En esta fase se presenta el vocabulario con el contenido fonético, en este caso el sonido [r]. Se pretende que el léxico seleccionado contenga este sonido en distintas posiciones y que, a su vez, sean elementos que en la vida cotidiana se tienden a asociar con diversas emociones. De esta manera, para representar la alegría sería: premio, reír, cantar, regalo, perdonar y amor. Para el miedo: rayo, ratón, relámpago, tiburón, vampiro, toro y araña. Para mostrar la tristeza: lágrima, suspender, guerra, arma, dolor, romper y llorar. Y para el enfado: gritar, tráfico, roncar y esperar. Se tiene en cuenta que este léxico no es una novedad para el alumnado ya que ha sido trabajado en la fase 1 de forma indirecta (en enunciados con las tres distintas entonaciones).

Se comienza, a modo de presentación/introducción, proyectando una de las imágenes (ver imagen 6) que representa el léxico descrito anteriormente. El estudiante tiene que nombrar qué palabra es, según aparezca. Para reforzar el componente emocional, el docente ayuda pronunciando con gestos, expresiones faciales y entonación adecuada 
para cada emoción, así el alumnado repite imitando al docente. Lo que se busca, en este caso es que el aprendiente mediante la asociación del propio componente emocional que genera cada imagen sea capaz de enunciar la palabra transmitiendo esa emoción.

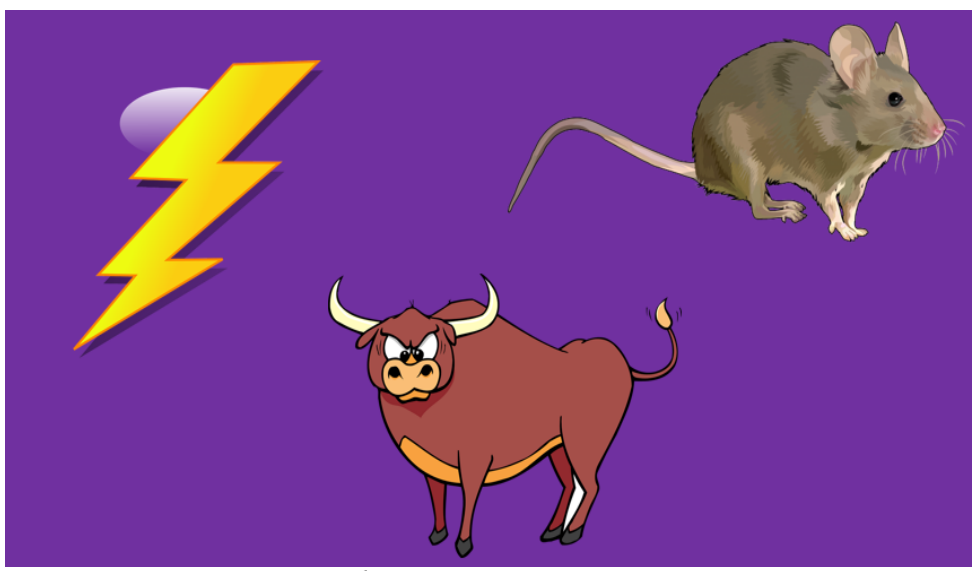

Imagen $6^{I}$. Léxico asociado al miedo

En esta última tarea, no se trata de que los estudiantes repitan, sino que van a formar sus propios enunciados, en función de lo que obtengan al azar. Se comienza mostrando a un personaje famoso, que incluya en su nombre el sonido [r], como es Shakira. Se comenta sobre ella (si la conocen, les gusta su música, etc.), anunciando al alumnado que, tras investigar sobre ella, hemos "averiguado" aquello que les gusta y que no les gusta. Por consiguiente, en segundo lugar, se proyecta una imagen en donde aparece una secuencia de tres imágenes. Los estudiantes, tienen que construir enunciados siguiendo la estructura: A Shakira le gusta/ no le gusta (algo). La dificultad viene en el hecho de que, como en la tarea anterior, el fondo viene representado de un color, que se asocia a una emoción, por lo que el aprendiente tendría que enunciar, por ejemplo: A Shakira no le gusta el ratón, intentando denotar miedo (ver imagen 7).

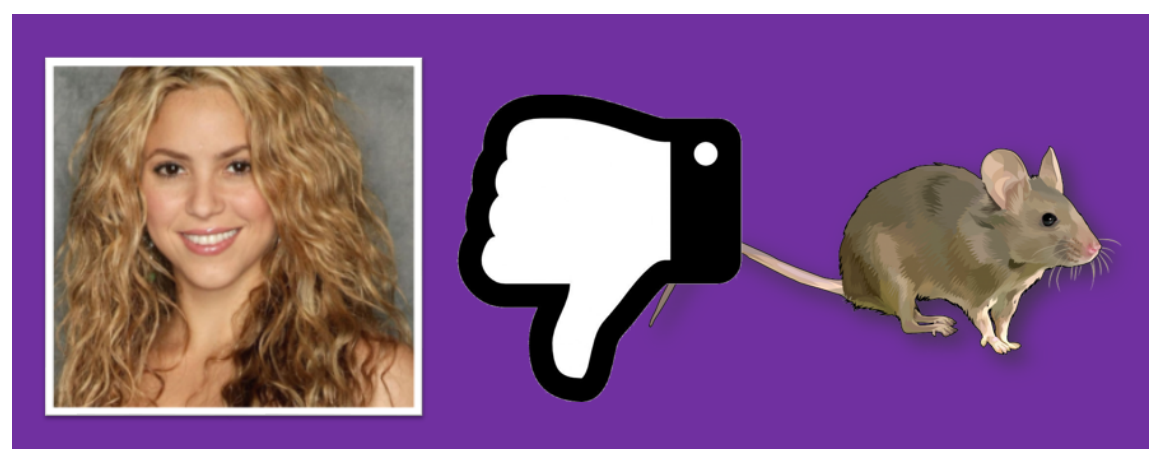

Imagen 7. Ejemplo de secuencia de imágenes para crear enunciados

Tras haber repetido este procedimiento varias veces con los aprendientes, haciendo diversas combinaciones de enunciados con otros personajes famosos, léxico y

\footnotetext{
1 El reconocimiento de la emoción viene facilitado además al disponerse para cada categoría de emociones, un fondo del mismo color que recuerde a cómo se expresaba el personaje de la película que representa, en este caso, el miedo, en morado.
} 
emociones y haberlo asimilado, se podría añadir un paso extra más. Se trataría de aplicar lo aprendido durante toda la sesión, lo cual implica mayor atención y asimilación por parte del estudiante. Se emplea para ello un dado de seis caras (ver imagen 8) que contiene los símbolos de las curvas melódicas presentados en la fase 1 (punto, signos de interrogación y puntos suspensivos). Ahora los estudiantes lanzan el dado y según el símbolo que obtengan, enuncian la frase anterior con una entonación determinada. Por ejemplo, al obtener el signo de interrogación asociado a la entonación interrogativa, sería: ¿A Shakira no le gusta el ratón?, recordando expresar la emoción de miedo.

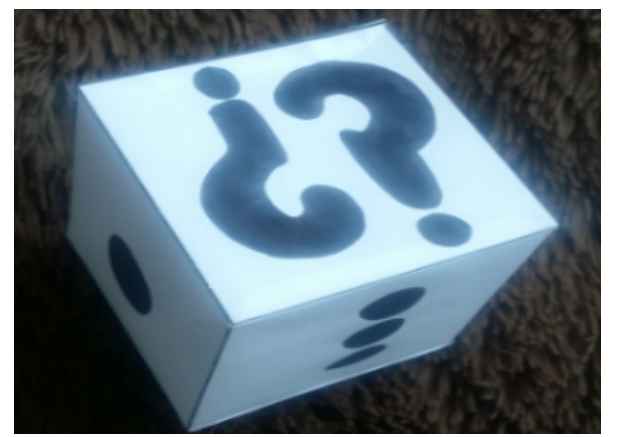

Imagen 8. Dado asociado a los símbolos que corresponden a las diferentes curvas melódicas

\section{Conclusiones}

Esta propuesta didáctica surge a partir de intentar favorecer en un determinado rango de estudiantes, como es los sinohablantes, la pronunciación del sonido [r], en asociación con un componente que va más allá de lo meramente lingüístico, asociado a valores pragmáticos, como es la entonación del español. Los destinatarios son unos aprendientes de nivel B1-B2, pero con ciertas carencias respecto a la lengua meta, el español, por lo que se pretende lograr una integración más factible en una comunidad de hablantes con la que chocan culturalmente: la hispana.

El propósito es transmitirles unos aspectos extralingüísticos que escasamente se pueden trabajar en una clase de aprendizaje de lenguas inactiva, tradicionalista y cerrada, como es la entonación. Mediante el empleo de los protagonistas de la película Del revés y sus emociones asociadas, los aprendientes pondrán en práctica la escucha y producción de estas empleándose, además, materiales y léxico adecuado y ameno que establezca en la clase una nueva forma de enseñar y aprender.

\section{Bibliografía}

Álvarez BAZ, Antonio (2012). El tratamiento de la interculturalidad en el aula con estudiantes de español sinohablantes (tesis doctoral). Granada: Universidad de Granada.

BERTOLA DE URGORRI, Mercedes (s. f.). La diferencia cultural y la pronunciación: dos aspectos a tener en cuenta en la enseñanza de español a alumnos chinos. Universidad de Centro Educativo Latinoamericano, Instituto Superior Parque de España. Recuperado de http://pad.usal.edu.ar/archivos/pad/docs/ugorri.pdf

BuENO Hudson, Richard (2013). «Propuestas para la enseñanza de la pronunciación y corrección fonética en español como lengua extranjera». Centro Virtual Cervantes. Recuperado 
https://cvc.cervantes.es/ensenanza/biblioteca_ele/publicaciones_centros/PDF/budapest 2013/04_bueno.pdf

CHEN ZHI (2011). «Errores articulatorios de los estudiantes chinos en la pronunciación de las consonantes españolas», SinoELE, 4, 54-67.

CRISTINA Alfonzo, Isabel y Yaiza SANTANA AlvARAdo (2015). «El choque cultural en el aprendizaje de ELE: alumnos sinohablantes de nivel A1». Centro Virtual Cervantes. Recuperado de https://cvc.cervantes.es/lengua/eaesla/pdf/01/01.pdf

FonT RochÉs, Dolors y Francisco José CANTERO SERENA (2008). «La melodía del habla: acento, ritmo, entonación», Eufonía: Didáctica de la música, 42, 19-39.

Planas Morales, Silvia (2007). «Enseñanza de la pronunciación del español en estudiantes chinos: la importancia de las destrezas y los contenidos prosódicos», RedELE, 17, 70-86.

RIVERA, Jonas (productor) y Docter, Pete y Ronnie Del CARMEN (directores) (2015). Del revés [cinta cinematográfica]. Estados Unidos: Pixar Animation Studios. 